\title{
Chicken Hepatoma
}

National Cancer Institute

\section{Source}

National Cancer Institute. Chicken Hepatoma. NCI Thesaurus. Code C134558.

Hepatoma that occurs in a chicken. 